\title{
Aid Effectiveness of Economics Development Initiatives of Sevanagala and Kebithigollewa Divisions Secretariat Divisions (DSDs): Are They Sustainable, Inclusive and Equitable?
}

\author{
Chatura Rodrigo
}

Institute of Policy Studies, Sri Lanka

Copyright $(2016$ by authors, all rights reserved. Authors agree that this article remains permanently open access under the terms of the Creative Commons Attribution License 4.0 International License

\begin{abstract}
Sri Lanka is a middle income country with a gross domestic production of about $\$ 50$ billion. The human development index places Sri Lanka at the $97^{\text {th }}$ position. Gender Inequality Index (GII) rank Sri Lanka at 74. The Gini index has reduced from 46 in 1995 to 40.3 in 2007; however, the economic inequalities are severe among rural areas. There is a significant discrepancy between the gender in terms of economic opportunities and economic status. The majority of Sri Lanka's workforce resides in rural areas and is engaged in agricultural activities. A significant share of the agricultural production is still used for self-sufficiency. Economic performance and poverty are not evenly spread across the nine provinces in Sri Lanka and serious regional disparities exist. Despite the many interventions by donor community and the government, there is a growing debate on the effectiveness of these aids on reducing the poverty of the rural Sri Lanka and ensuring sustainable, inclusive and equitable growth. This study looked at Uva and North Central provinces where the poverty rates are extremely high while donor interventions on economic development are high as well. Level of success derived from donor funded economic development projects vary based on the duration of the project where some instances such as adaptation to new and environmentally friendly agriculture farming methods are only being introduced through long term projects yet failing to motivate the youth. There are disparities among the women headed households in receiving the livelihood supports both short and long term. While male headed households are more successful in utilizing economic development initiatives to ensure their livelihoods, female headed households have failed to do so.
\end{abstract}

Keywords Economic Development, Gender, Long and Short Term Aid Programs

\section{Background}

More than a statement of general principles, the Paris Declaration of 2005, lays out a practical, action-orientated roadmap to improve the quality of aid and its impact on development. It puts in place a series of specific measures for implementation and establishes performance indicators that assess progress. Ownership, alignment, harmonization, managing for results and mutual accountability are the five main principles that are agreed up on in effective aid management. By implementing these principles, the countries and organizations that endorsed the Paris Declaration are making major breakthroughs in improving aid effectiveness, tackling issues that have hampered development for decades. Developing country governments and civil society are reaping the rewards in the form of better, more aligned and more predictable donor support (OECD 2008).

Development aid fell by $4 \%$ in real terms in 2012 , following a $2 \%$ fall in 2011 . The continuing financial crisis and euro zone turmoil has led several governments to tighten their budgets, which has had a direct impact on development aid. There is also a noticeable shift in aid allocations away from the poorest countries and towards middle-income countries. The United States continued to be the largest donor by volume with net ODA flows amounting to USD 30.5 billion in 2012 , representing a fall of $-2.8 \%$ in real terms compared to 2011. Many other major donors recoded a similar reduction in their support to developing countries. While future outlook suggest that there will be a shift in aid towards middle-income countries in the Far East and South and Central Asia, primarily China, India, Indonesia, Pakistan, Sri Lanka, Uzbekistan and Vietnam, it is utmost important that these aid be used in an effective manner, in line with the principles of the Paris Declaration of 2005.

Majority of Sri Lanka's aid flow have been from Japan, ADB and Work Bank, but China, India, United States 
(through US Aid) and Australia (Aus Aid) have also become significant donors to Sri Lanka in the recent past. Multilateral aid flow to Sri Lanka declined recently when the per capita income increased above USD 2000. Uses of the foreign aid are many. However, majority of the foreign aid to Sri Lanka in a post war situation is mainly for infrastructure development and economic development which mainly looking at improving livelihoods and reducing poverty of rural agricultural communities (Sunday Observer, 2011).

Economic development projects, especially the donor funded ones happen through the government institutions, private sector and NGO/INGOs. Ministry of Economic Development is the main entity that handles donor funded economic development projects in Sri Lanka which channels through the government. At the moment there are 31 such projects, values at 130,000 billion rupees. They are mainly funded through World Bank (WB), Asian Development Bank (ADB), and Japan International Corporation Agency (JICA), (Ministry of Economic Development, 2013). In addition there are many NGO/INGOs such as World Vision Lanka, Sarvodaya, Practical Action and Sevalanka that are pioneered in economic development projects in Sri Lanka. The amount of money spent on these projects, physical and human resource involvements and the number of beneficiaries covered is very high in these projects. However, whether these projects have created the desired outcomes, whether they have addressed the neediest beneficiaries is largely at debate, raising the issues of aid effectiveness. Further, it is a major concern that whether these economic development projects have been able to ensure equity and inclusiveness, especially inclusion of women.

In this regard, this research aims to look at the effectiveness of aid, focusing on the economic development projects in Sri Lanka but mainly concentration on Uva and North Central provinces. Uva and North Central provinces comprise of some of the poorest areas of Sri Lanka. These areas are limited with infrastructure facilities such as electricity, safe drinking water, safe housing and safe sanitation. In addition, the transport infrastructures in these areas are also poor limiting the marketability of agricultural commodities, as the main occupation in these areas is farming. However in order to help the vulnerable and marginalized communities in these regions there are numerous development projects are on the way implemented by the government, private and the nongovernmental sector.

From these two provinces, Sevanagala and Kebithigollewa DSDs were selected since they represent a poor farming community and there are plenty of economic development projects directed towards them through the government as well as NGO/INGOs. There are many ways to look at the aid effectiveness, but this research selected a less sophisticated method. Economic development projects have many activities and there are programme monitoring indicators. After a thorough literature review, this research selected five such indicators which are common to all the economic development projects selected for this research which are in place at the moment in Sevanagala and
Kebithigollewa DSD. Each of these indicators was then looked at from a long term Vs short term project perspective and the gender of the farm household perspective. In doing so this research aims to address the research problem of "are economic development aid to rural farming households a success story, in bringing about sustainable inclusive and equitable economic growth"?

\section{Methodology}

Primary data for this research was collected using both qualitative and quantitative techniques. Qualitative data collection was through of Key Informant Interviews (KII) and Focus Group Discussions (FGD), while quantitative data was collected using household surveys. Data was also collected from secondary sources, thorough literature and document review and from the relevant government offices. A wide range of perspectives regarding the project implementing agency's interventions were obtained through methodological triangulation, (for example, collection of data using various methods and from different sources), thus improving the validity and reliability of the results. Data collection tools were designed to capture the necessary first-hand information from the communities.

The household survey was carried out using an interviewer administrated questionnaire. The survey data was recorded via Personal Data Assistants (PDAs). The survey sample consisted of 100 families per each Divisional Secretariat Division (DSD) area. For Sevanagala DSD, The 100 families were selected from five selected Gramaseva Niladhari Divisionss (GND): Habarugala, Mahagama, Weliyara, Nugegalayaya and Muthuminigama. For Kebithigollewa DSD also, the 100 families were selected from five GND's: Halmillawetiya, Wahalkada, Thammennawa, Gonumeriyawa, and Kungpuchchiya. The survey sample included respondents who were beneficiaries of short term as well as long term projects.

Table 1. Household Survey Sample

\begin{tabular}{|l|c|}
\hline \multicolumn{1}{|c|}{ Category } & Number of Interviews \\
\hline $\begin{array}{l}\text { Sevanagala: Beneficiary families (mix of } \\
\text { gender, and whether long term or short } \\
\text { term project) }\end{array}$ & 100 \\
\hline $\begin{array}{l}\text { Kebithigollewa: Beneficiary families (mix } \\
\text { of gender, and whether long term or short } \\
\text { term project) }\end{array}$ & 100 \\
\hline \multicolumn{1}{|c|}{ Total interviews } & 200 \\
\hline
\end{tabular}

Focus Group Discussions (FGDs) and Key Informant Interviews (KIIs) were held with community members including male and female headed farm households. All the KIIs and FGDs were digitally recorded in Singhalese (with prior consent from the participants). Upon completion, all the interviews were translated into English and the transcripts were used for first and second level qualitative analysis. Quantitative data analysis was done using statistical software STATA. In addition, a through literature survey 
was also done using the documents shared by the relevant government organizations and NGO/INGOs in the two areas. Figures 1 and 2 below highlight GND areas selected for quantitative surveys, KIIs and FGDs.

This study focused on looking at the aid effectiveness of economic development projects of both long term and short term, at community levels. Short term projects ranged from 1-2 years while long term projects ranged from 2 years or more. From both DSDs, there were 10 GNDs selected which contains both long term and short term donor funded projects. These projects were not only aiming at economic development rather they were also looking at other issues such as health and nutrition, education, and society development of the communities, however the scope of this research is limited to the economic development component of the project.

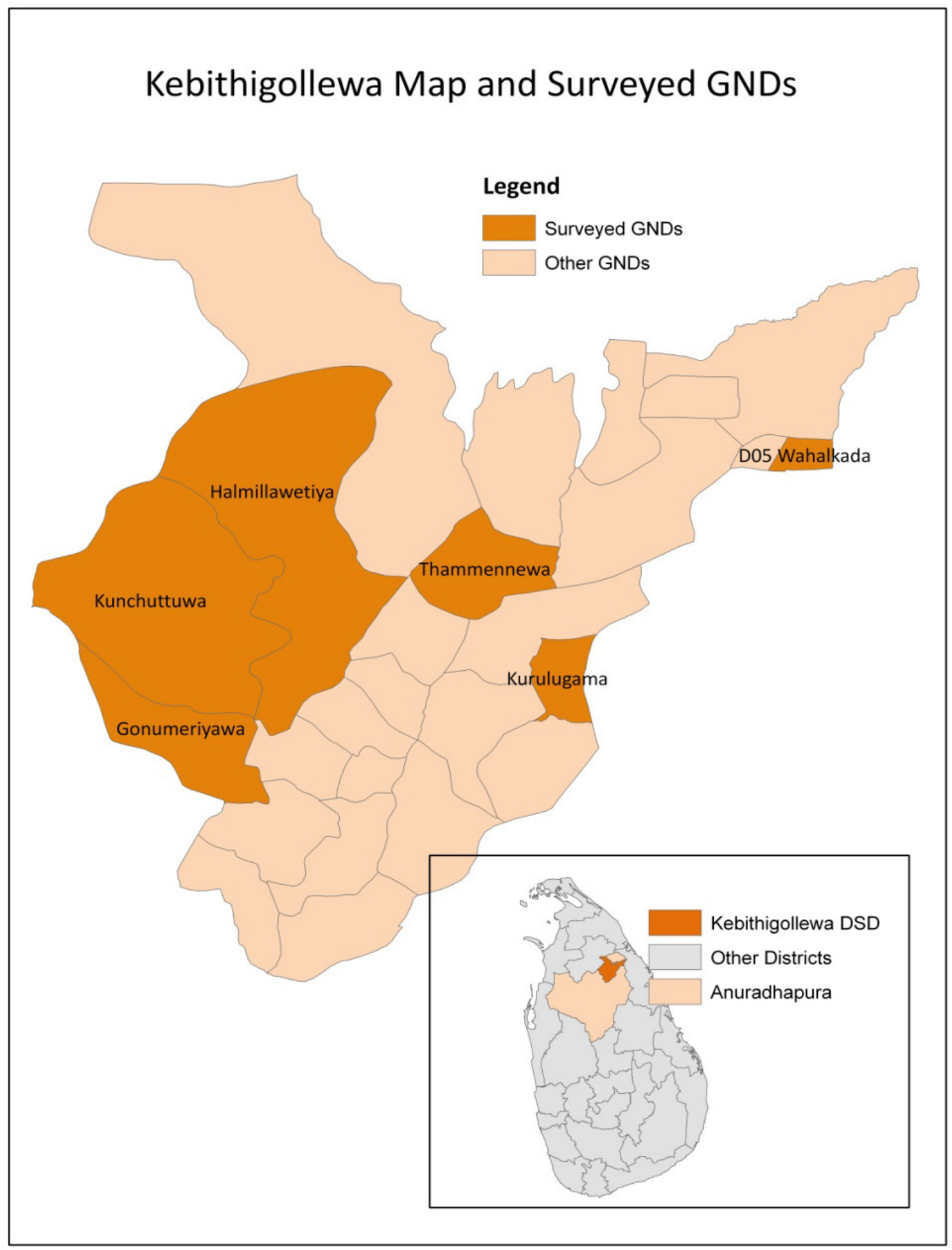

Figure1. Kebithigollewa DSD and the GNDs where the Household Survey was conducted 


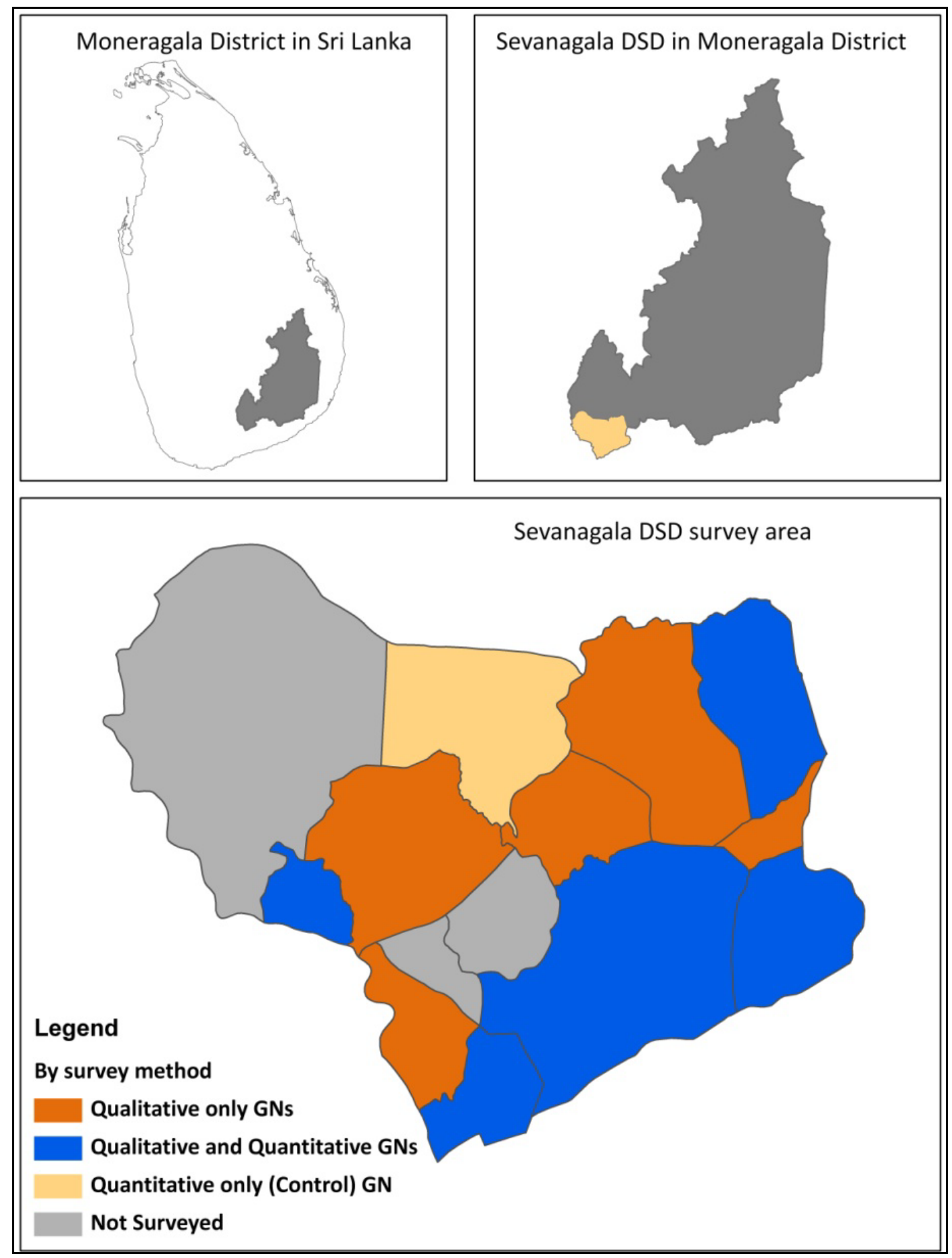

Figure 2. Sevanagala DSD and the GNDs where the Household Survey was conducted

\section{Findings}

Analyzed findings of the quantitative and qualitative research and literature review are presented under the main programme component of all the selected short term and long term programmes: Economic Development. However, as mentioned earlier, it should be noted that most programmes have additional components such as health and nutrition, education and society development. Yet, economic development is considered as the component for comparison since it is the scope of the study as well as economic development is the largest component compared to other. Findings are presented collating information for both Sevanagala and Kebithigollewa DSDs and further findings will not be disaggregated based on the GN division since the selected GNs shared a similar socio-economic profile. However for the DSDs a distinction will be made where necessary.

Following section will first look at the profiles of farmers in the two DSDs using some basic socio-economic indicators, 
and then will evaluate the aid effectiveness from several criteria. These criteria are: selection of the correct beneficiaries for the programmes, adaptation of new agro technologies and environmentally friendly agricultural methods (traditional paddy varieties, use of organic farming and traditional framing systems), improvements in the access to markets and becoming competitive, changes in the financial liabilities and improvements in household income and expenditure status. These indicators will be looked at from a project duration (whether the project is long term or short term) and gender (whether the household is a male headed or female headed). The argument behind this analysis is to see whether the realizations of the benefits from economic development intervention (proxied by the indicators mentioned earlier) vary based on the project period and the gender of the head of the household.

The goals of the economic development activities were to increase household income in the Sevanagala and Kebithigollewa DSDs. It aimed to increase agricultural income and possibilities of spending by promoting new and environmentally friendly agricultural techniques, enhanced marketing facilities and competitiveness and reducing the dependence on financial liabilities. Another aim was to increase alternative income sources by improving vocational skills of youth and adults, and by introducing self-employment opportunities and small group level businesses. Project activities under these objectives included, for example, promotion of loan facilities, arranging workshops and trainings and distribution of equipment according to small groups' business plans. Animal husbandry was improved with regard to bee keeping and rearing cows for dairy. Community participation in the economic development sector was increased via training in management skills (time, accounting and reporting), improved monitoring techniques, and networking with governmental and non-governmental entities on economic development. The project intervention areas are highly agricultural driven. Considering the Sevanagala and Kebithigollewa DSDs, over half (56\%) of the population is employed in the agricultural sector, whereas close to 17 percent is employed by private sector. Another 17 percent of the active labour force is currently unemployed (looking for employment); the figure does not include those who choose not to engage in the labour force, such as housewives. Buffaloes are the most common type of livestock, followed by poultry and cattle. However, farmers of Sevanagala DSD were more diversified, where majority of farmers had secondary income sources in addition to agriculture. The monthly household income captured by the survey includes the income from the primary income source (agriculture ${ }^{1}$ ), the secondary income source; subsidies from the government/INGOs/NGOs and any other remittances. In Kebithigollewa DSD, 65 percent of the households have a monthly income below LKR 15,000, while in the Sevanagala DSD this figure is 48 percent. In Sevanagala, approximately $50 \%$ of farmers were having a monthly income between LKR15, 000-20,000 (Figure 3). Overall the households in the Sevanagala DSD seem to have higher income levels. This difference can be attributed to the high dependency in agriculture in the Kebithigollewa DSD, which is not considered as a stable income source given the circumstances such as variability and uncertainty in agriculture production. The income levels measured through the survey are higher than income levels presented in government statistics ${ }^{2}$, which show that only about 21 percent of households earn a monthly income above LKR 10,000 .

Selection of the correct beneficiaries for the programmes: For long term projects, the perception on importance of the economic development activities is highest among the middle income group. For the higher income group, these interventions could be less important since they already have a means of sustenance. On the other hand, the lowest income group perceived these interventions as less important than the middle income group. However, in short term projects, lowest income people's perception was higher on the importance of economic activities than all other groups. This trend is equally observed in both Sevanagala and Kebithigollewa DSDs. This is partly due to the beneficiary selection process and their criteria of selection. For examples, most long term projects that selected farmers for planting material distribution only looked at farmers who had more than 1.5 acres. Most of the lowest income groups were excluded from the assistance under these selection criteria. Additionally, long term interventions usually focused on setting up community based organizations (CBOs) to mainstream their work. Therefore, whoever that was not part of their CBO group were left out from most economic development initiatives or they were the last to be considered. Most of the poorest people were struggling to make daily survival, hence not that prompted to go after becoming CBO members; hence they were most of the time left out. Short term projects did not require these sorts of essentials when working with the communities; therefore they were effectively catering to the neediest. On gender, both long term and short term projects were not that considerate having a gender balance in selecting the farmers, for their programmes. These programmes have rarely attempted to select farmers based on the male: female headed household ratios in the area. Most have used lists provided by the local authorities or used their own field officers recruited from the same localities. Therefore, there is visible biasness in selecting equitable and inclusive set of beneficiaries. 


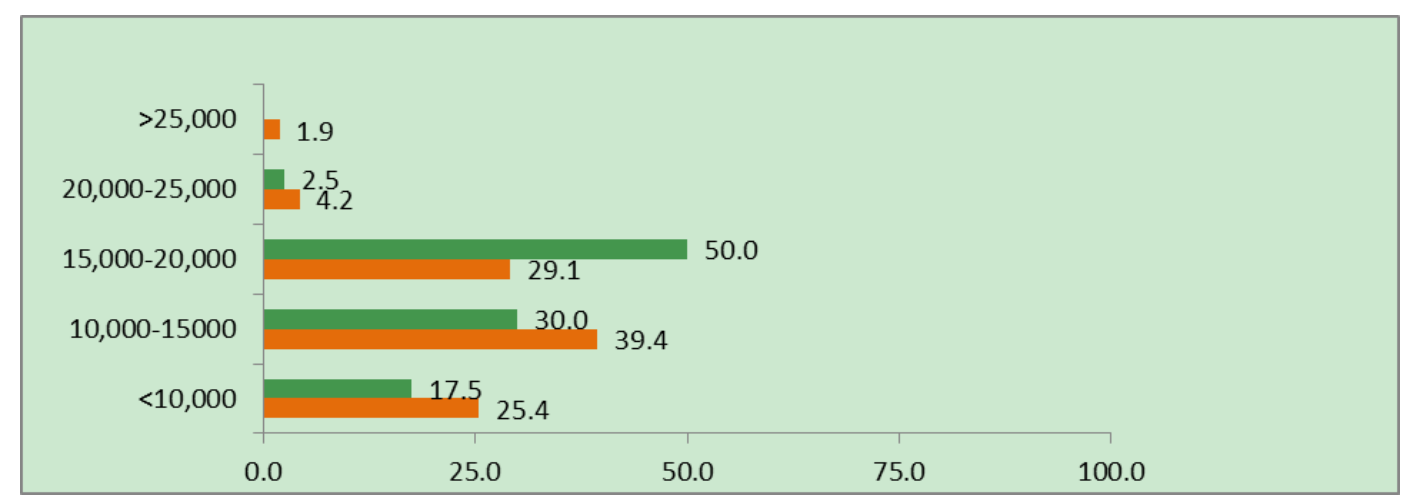

Figure 3. Average Monthly Household Income

Adaptation of new agro technologies and environmentally friendly agricultural methods: An important aspect that economic development programmes look at is the readiness of the farmers to adopt new agro-technologies. Results revealed that there is a greater readiness among older farmers to adopt new agro techniques when it comes to long term projects. The younger farmers appear to be less interested in pursuing agriculture for livelihood and those that do also appear to be less interested in new and environmentally friendly agro techniques. This implies that the younger population would require stronger incentives to stay in agriculture. All most all long term projects had a component to introduce new and environmentally friendly methods of cultivations however short term projects hardly had these kinds of interventions. In a way this could be justified since adaptation to new farming methods, especially environmentally friendly methods takes time. Short term programmes were more on to introducing new machinery but not on new and environmentally farming methods. Therefore, while long term projects had the necessary conditions for sustainable development, they were attracting older beneficiaries. However, I believe the future of Sri Lanka's agriculture is rest on the hand of the youth. Therefore, to that argument, long term projects failed in securing the sustainability of the programme. On a gender perspective, the survey, FGDs and KIIs confirmed that female households were reluctantly engaging on being exposed to new and environmentally friendly farming methods, which were delivered mainly through long term projects. However, the research could not identify a direct reason for this difference, yet some female framing households mentioned their uncertainty in the profit making ability of the environmentally friendly farming methods.

Improvements in the access to markets and becoming competitive: Provision of support to farmers to find markets for their products and helping them to become more competitive in the market place was done both through long term and short term projects. Improving access to market places does not necessary take a longer time as in the case of adaptation to new and environmentally friendly farming technologies, hence both term projects were also successful in both Sevanagala and Kebithigollewa DSDs. In Sevanagala approximately $48 \%$ farmers mentioned that the programmes have helped them to find new markets for their products as well as encouraged and made them more competitive and they did not see a significant different between long and short term projects. This situation is similar in Kebithigollewa DSD, where approximately $51 \%$ of farmers said that programmes have helped them in this perspective, and there also, no clear difference between long and short term projects. Whether the farmer would establish or find new markers or whether they would be more competitive would not differ whether the household is male headed or female headed. This was conformed through the survey, FGDs and KIIs. This shows that the importance of becoming more competitive and ensuring profits is equally perceived by male and female headed households.

Changes in the financial liabilities: Financial liabilities could act as a catalyst we well as a barrier for farmers. Financial support can help farmers to extend their cultivation, be more marketable and earn more profits. However, agriculture production is highly uncertain. Country's economic conditions and climate conditions such as heavy rainfall, droughts and floods can destroy the harvest. This could drive farmers to borrow more, ultimately dragging them to the vicious cycle of poverty. Uncertainties in agriculture sector have increased over time, temperatures have changed and rainfall patterns (both intensities and amounts) have also changed. This has resulted in farmers becoming more vulnerable and prompted for financial liabilities. This situation has created a significant difference between the long and short term projects. In the Sevanagala DSD, long term projects were not capable of reducing the financial liabilities of farmers, where in Kebithigollewa DSD, long term projects have been successful. Furthermore, short term projects in both DSDs have not managed to reduce the financial liabilities of farmers significantly. This result shows the significance of the uncertainties in agriculture, the changes of climate, which has increased the farmer's vulnerabilities. This also suggests that the short term economic development projects might not be a suitable solution to address the inevitable phenomenon such as climate change. The main reason behind the Sevanagala farmers being successful in the context of long term projects is that farmers were more diversified where majority of them had secondary income sources. Regardless of being a 
beneficiary of a long term project or a short term project, in both Sevanagala and Kebithigollewa DSDs, female headed households were more in to financial liabilities. A direct reason could not be found for this through the survey, FGDs or KIIs, but this could link to the fact that majority of female headed households were only engaging agriculture, where majority of the male headed households has secondary livelihoods.

Improvements in household income and expenditure: Average monthly income and expenditure on goods and services of the farm households increased overtime in both Sevanagala and Kebithigollewa DSD. On might argue that this couldn't only be necessarily due to the economic development initiatives and it could also be due to the general economic growth of the country. However, when asked, majority of farmers form both Sevanagala and Kebithigollewa DSDs agreed that their average monthly income went up with the exposure to the economic development projects. Short term projects were more successful in creating impacts on increasing the average monthly income and expenditure on goods and services of farming households compared to long term projects in both Sevanagala and Kebithigollewa DSDs. The income and expenditure increases were mainly with the direct financial and material benefits that farmers have received and not much linked to the skills training and awareness they have received. Short term projects were more in to providing financial and material assistance such as planting seeds, plants and animals while long term projects were more in to skills development and awareness. These findings does not confirm that the programme modality of the long term projects are wrong, however it highlight the fact that people put more emphasis on financial and material assistance compared to skills and awareness development. Average monthly income and expenditure of the female headed households at both Sevanagala and Kebithigollewa DSDs, regardless of being exposed to long term or short term projects rose at a lower rate compared to male headed households. This is again is not directly explained through the survey, FGDs and KIIs, but could be due to the fact that female headed households are more tide up with financial liabilities and the majority of them only dependent on agriculture, without an secondary income source.

\section{Conclusions}

In securing aid effectiveness of economic development projects, long term and short term projects are successful at different levels. However, on average it is clear that short term projects are more successful creating impacts especially selecting the neediest and reducing the financial liabilities and improving income and expenditure status of farm families. While long term projects were successful in promoting new and environmentally friendly agriculture practices, they have mainly catered to the aged farmer population where the youth are left out. Both long and short term projects were successful in helping farmers to secure new markets and becoming competitive. Therefore, whether aid effectiveness of economic development projects has mixed effects based on short term and long term projects. Hence it should be looked more closely relating to the programme objectives and socio-economic conditions of the beneficiaries.

However, on the outset given the current development needs of the country the short-term projects are much more suitable. Short term projects would raise the income of the farmers better than long-term projects and that is an immediate goal of the development efforts of the government. Furthermore labour out migration, especially the abandoned of agriculture as an occupation by the youth is a major issue in Sri Lanka. The results of the study suggest that the short-term projects in comparison are better in generating more youth oriented employment opportunities. Therefore in that aspect also the short-term projects address the immediate development needs of the government. The only significant negative impact that the short-term projects have is that they do not yield environmental benefits. This is in a way true to a certain extent since environmental benefits take a longer time to yield. Therefore one cannot expect environmental benefits in the short run from development projects. Hence it can be concluded that the short-term development projects are much more successful in aid effectiveness in Sri Lanka.

A proper baseline study and needs assessment would help to tackle this issue. However economic development programmes, whether they are long term or short term have largely failed to be equitable and inclusive, resulting gender disparities. Many programmes have failed to select their beneficiaries based on the male and female headed composition of the community, and female headed households were not looked at from a vulnerability point of view. Therefore, for many indicators, female headed households have not been successful in realizing the economic benefits which questions the aid effectiveness from a gender perspective. In the future is very essential that female headed households are treated as vulnerable, and project monitoring and evaluation should be done around them. One suggestion is to adopt concepts such as "sustainable livelihood frameworks" where female headed households become a central part of the economic development programme.

\section{REFERENCES}

[1] Karunagoda, K. 2004, " Changes in Labour Market and Domestic Agriculture" Sri Lnaka Journal of Agriculture Economics, Vol 6, No 1, pp 82-97.

[2] Sri Lankan National Agricultural Policy, Ministry of Agricultural Development and Agrarian Services.

[3] Dissanayake, C.B. (2005). Water quality in the dry zone of Sri 
Lanka - some interesting health aspects. J. Natn.Sci.Foundat ion Sri Lanka 2005 33(3): 161-168.

[4] The World Bank (2011). Sri Lanka: Priorities for Agriculture and Rural Development.

[5] World Bank, 2013, "Sri Lanka Priorities for Agriculture and Rural Development", http://web.worldbank.org/WBSITE/EX TERNAL/COUNTRIES/SOUTHASIAEXT/EXTSAREGTOPA GRI/0, contentMDK:20273817 menuPK:548217 pagePK:3 4004173 piPK:34003707 theSitePK:452766,00.html Accessed date: May 10, 2013.

[6] Daily News, Tuesday 24 May 2011. Farmers advised to use carbonic fertilizer. Nimal Wijesinghe. $<$ http://www.dailynew s.lk/2011/05/24/news18.asp>16.4.2012.

[7] Headcount Index and Population Below Poverty Line by DS Division - Sri Lanka: 2002. Department of Census and Statistics. <http://www.statistics.gov.lk/poverty/small\%20ar ea\%20report $N E W . p d f>30.4 .2012$.

[8] Poverty Indicators. Household Income and Expenditure Survey 2009/10. Volume 1, Issue 2, May 2011. Department of
Census and Statistics Sri Lanka<http://www.statistics.gov.lk/ poverty/PovertyIndicators2009_10.pdf> 30.4.2012.

[9] Poverty in Sri Lanka (Based on Household Income and Expenditure Survey -2006/07). Department of Census and Statistics, Ministry of Finance and Planning Sri Lanka.<http://www.statistics.gov.lk/poverty/reportnew-Final .pdf> 30.4.2012.

[10] OECD, 2008, “The Paris Declaration on Aid Effectiveness: Five Principles for Smart Aid", www.oecd.org/dac/effective ness.

[11] Sunday Observer, 2011, "Drop in US Aid, no surprise, China: Top Most Aid Provider, http://www.sundayobserver.lk/2011/07/31/fea30.asp.

[12] Ministry of Economic Development, 2013, "Regional Developments: Donor Coordination and Project Management of Foreign Funded Projects", http://med.gov.lk.

[13] Jayanath's Weblog; Unemployment Problem in Sri Lanka (2008), <http://jayanath.wordpress.com/2008/07/06/unempl oyment-problem-in-sri-lanka/> Accessed date: May 10, 2013. 